\title{
UMA EXPERIÊNCIA DE UTILIZAÇÃO DA REVISTA VIRTUAL DE HISTÓRIA DA BIBLIOTECA NACIONAL NO ESTUDO DE TÓPICOS DE HISTÓRIA DO BRASIL COLONIAL
}

\begin{abstract}
AN EXPERIENCE OF USING THE JOURNAL OF HISTORY OF THE NATIONAL LIBRARY - VIRTUAL - NO STUDY TOPICS COLONIAL HISTORY OF BRAZIL
\end{abstract}

Laura Nogueira Oliveira ${ }^{1}$

RESUMO: Mostra a experiência de utilização da Revista de História da Biblioteca (RHBN), disponibilizada on-line, com alunos de primeiro ano do ensino médio de uma escola técnica da rede federal de ensino. Discute-se a importância e a pertinência da construção de roteiros de trabalho para atividades discentes, com a utilização da web, descrevendo-se os passos a serem executados pelos estudantes. Apresenta-se também uma possibilidade de utilização do rico acervo da RHBN, disponibilizado na internet, para realização de atividades de ensino em nível de Ensino Médio.

Palavras-Chave: Revista. Ensino de História. Ensino Médio. Brasil Colonial. RHBN.

\begin{abstract}
Experience report of use of the Revista de História da Biblioteca (RHBN), available online, with first-year students of a high school technical school federal education network. It discusses the importance and relevance of building roadmaps work activities for students, using the web, describing the steps to be performed by students. It presents also a possibility of using the rich collection of RHBN, available on the Internet to carry out teaching activities in high school level.
\end{abstract}

Keywords: Magazine. Teaching of History. High School. Colonial Brazil. RHBN.

\section{Introdução}

${ }^{1}$ Professora de História do Departamento de Geografia e História do CEFET/MG. Doutora em Literatura Comparada. 
Objetivo mostrar uma experiência de utilização da Revista de História da Biblioteca (RHBN), disponibilizada on-line, realizada com alunos de primeiro ano do Ensino Médio de uma escola técnica da rede federal de ensino. Discuto a importância e a pertinência da construção de roteiros de trabalho para atividades discentes, com a utilização da web, descrevendo-se os passos a serem executados pelos estudantes. Acostumados a explorarem a web, os jovens em uma cultura midiática são propensos a se interessarem por trabalhos deste tipo. Contudo, embora pareça simples o passo a passo proposto neste artigo, considero que o jovem estudante não transpõe seus com conhecimentos próprios da cibercultura para a pesquisa escolar, $\mathrm{n}$ ocaso, no que diz respeito ao ensino de história. Apresento também uma possibilidade de utilização do rico acervo da RHBN, disponibilizado na internet, para realização de atividades de ensino em nível de Ensino Médio.

\section{Ensino de história na cibercultura}

Muito se tem demandado de nós professores a utilização das Novas Tecnologias da Informação e Comunicação - NTICs - no ensino regular e presencial. Segundo Circe Bittencourt (2004), um dos pressupostos que orientada as propostas de renovação dos métodos de ensino e, entre eles, o ensino de história, é o da necessidade premente de articular as novas tecnologias de informação aos métodos e aos conteúdos de ensino. Afinal, as transformações tecnológicas produziram, nas últimas décadas, gerações de jovens pertencentes a uma "cultura de mídias", pois elas deram nova feição às formas de comunicação humana e permitiram a introdução de outros referenciais para produção do conhecimento. Jovens e crianças convivem, cotidianamente, com computadores, videogames e inúmeras outras variantes midiáticas, numa cultura emergente marcada por formas interativas de relacionamento.

Na mesma direção aponta o professor Marcos Silva (s/d). Baseandose em dados de pesquisa do IBGE e IBOPE, o professor destaca que, se a 
infoexclusão ainda é uma realidade do país, ela vem sendo progressivamente vencida. Ele apresenta números levantados em 2006 por pesquisas que indicam que $45,7 \%$ da população brasileira já fez uso do computador e que 33\% já navegou na internet. Diante de uma realidade de gradativa superação da exclusão digital, Silva convida os professores a refletirem sobre a possibilidade de sobrevivência de uma escola que se mantém distante e afastada de uma cultura cada vez mais marcadamente midiática. Em sua avaliação, não há mais espaço para uma "prática pedagógica de resistência" à "avalanche de imagens e sons que domina a vida das pessoas atualmente", sendo a exigência contemporânea a incorporação "dos recursos da telemática à práxis pedagógica" (SILVA, s/d). Para Silva, existe um crescente hiato entre o modo de fazer da escola e a vivência cotidiana das crianças e jovens da denominada geração net. A nova geração que chega ao espaço escolar, afirma, "não se satisfaz com a linearidade dos livros" e "exige interatividade". A seu ver, resta aos professores a "incorporação dos recursos da telemática à práxis pedagógica" e uma nova postura metodológica.

No que se refere ao ensino de história, Silva afirma que a área é "uma das mais adequadas para a incorporação" das novas tecnologias de informação. E isto porque, informa seu leitor, encontra-se na internet uma quantidade inimaginável de material apropriado ao ensino deste conteúdo escolar, tais como documentos, documentários, textos literários, músicas, imagens - de pinturas, de charges - entrevistas e filmes. É possível o professor organizar até mesmo visitas virtuais a Museus nacionais e estrangeiros. ${ }^{2}$

Porém, inúmeras são as questões a serem enfrentadas por aqueles que se decidem a utilizar as novas formas midiáticas e as possibilidades por elas oferecidas, no processo de ensino-aprendizagem. Para Circe Bittencourt, se, por um lado é preciso superar a visão das novas tecnologias como inimigas, por outro, não se deve utilizá-las "sem uma crítica profunda

\footnotetext{
${ }^{2}$ A possibilidade de visitas virtuais a museus foi facilitada com a criação do site Era Virtual Museus, que disponibiliza o acesso a várias instituições brasileiras. Disponível em: http://www.eravirtual.org/pt/ Acesso em 20 set. 2012.
} 
do que transmitem, das formas individualistas de comunicação (...) que estabelecem, do fortalecimento do ideário de uma submissão irrestrita ao domínio da máquina como instrumento educativo" (BITTENCOURT, 2004, p. 109). Para a autora é preciso desenvolver no aluno a preocupação de criticar, de forma permanente e profunda, o que está lendo nos sites e blogs acessados. Afinal, um dos riscos que se corre é o de desenvolver práticas e usos alienados. Se as atuais propostas curriculares e de renovação nos métodos de ensino demandam a inclusão das novas tecnologias, tais suportes precisam ser analisados segundo suas possibilidades paradoxais: ao mesmo tempo em que geram inúmera contribuições são também enormes os problemas a serem enfrentados.

Marcos Silva, por sua vez, lembra que, se o professor do futuro é aquele capacitado para selecionar informações e para torná-las acessíveis, é preciso construir claros roteiros de orientação para os alunos, com "objetivos concretos e um itinerário sugerido". Não se trata, segundo o autor, de deixar os alunos navegarem livremente, sem posse de "ferramentas instrucionais". Cabe ao professor, portanto, o planejamento, o desenvolvimento e a aplicação de "situações didáticas ambientadas no ciberespaço" (SILVA, s/d).

\section{Desafios}

A partir das reflexões dos autores citados, acredito que três desafios se apresentam ao professor. Existem, por um lado, os problemas que chamarei de ordem autoral e que dizem respeito à simples cópia de textos escritos por outras pessoas. Na era da informática e do "ctrl t", "ctrl c" e "ctrl v" (seleciona, recorta e copia), inúmeras são as questões que o professor pode se colocar. Assim, como conseguir que os trabalhos apresentados pelos alunos não sejam uma simples impressão de textos encontrados na web? Como impedir que os trabalhos se limitem a uma simples montagem de trechos de textos encontrados em sites diversos? Como saber que o material encontrado nos sites pesquisados foram lidos e 
apropriados e não apenas copiados? Como garantir que o trabalho proposto seja realizado e construído pelos alunos? Como evitar que a utilização da internet pelo aluno repita o trabalho mecânico de cópia de respostas previamente já existentes?

Ao lado desta preocupação e diretamente a ela ligada, existe aquela referente à confiabilidade das informações obtidas. Afinal, como garantir que os sites visitados pelos alunos sejam seguros no que se refere às informações neles contidas? Ou, como confiar nas informações que serão encontradas e estudadas pelos alunos? Simultaneamente, como possibilitar aos alunos o acesso a sites adequados para o uso no espaço escolar e para fins educacionais, particularmente para o ensino da história?

Por fim, estão os desafios relacionados à adequação dos trabalhos propostos aos meios a serem utilizados. Se a internet, dentre outras formas midiáticas, destaca-se pela incomensurabilidade das informações que contém, sua marca está na interação permanente e na busca infinita que se abre para o internauta. Como construir trabalhos escolares que sejam capazes de despertar a curiosidade dos alunos ao apresentar-Ihes desafios a serem superados? Será possível conceber trabalhos que desencadeiem atividade de produção e/ou de criação por parte dos educandos?

\section{A RHBN e o ensino de história}

Publicada pela Sociedade de Amigos da Biblioteca Nacional (SABIN), com apoio do Ministério da Cultura e patrocínio da Petrobras e outras grandes empresas, sob o amparo da Lei Rouanet, a Revista de História da Biblioteca Nacional (RHBN) tem-se destacado pela divulgação da moderna e atualizada historiografia brasileira, revelando tendências e perspectivas teóricas e metodológicas da área. Os artigos publicados em suas páginas são selecionados por reconhecidos especialistas da área e, acredito, a Revista tem alcançado largo reconhecimento entre os historiadores. ${ }^{3}$ Deste

3 Uma demonstração do reconhecimento da qualidade da Revista de História da Biblioteca Nacional seja a utilização de seus artigos para a elaboração de questões 
modo, é possível encontrar nas páginas da RHBN material histórico e historiográfico produzido e/ou selecionado - sejam imagens, textos, documentos e indicações bibliográficas - de alta qualidade.

Se a existência da Revista deve ser festejada pela possibilidade de divulgação das pesquisas e do conhecimento histórico para o público especializado e a população em geral, a criação de seu site http://www.revistadehistoria.com.br/v2/home/ - e a disponibilização de seu material on-line possibilitam sua utilização como material escolar. Um verdadeiro convite ao professor. Afinal, como deixar de apresentar aos alunos aquilo que a área tem produzido? Como privá-los do conhecimento de um material de alta qualidade acadêmica resultado do trabalho de inúmeros especialistas? Por outro lado, mesmo se tratando de material de divulgação científica, como realizar sua transposição didática (CHEVELLARD, 1991), isto é, sua adequação para usos em espaços escolares?

Contudo, restam as questões acerca da proposição de trabalhos pedagógicos que procurem dar respostas às questões anteriormente levantadas, no que se refere ao uso do ciberespaço. Ou seja, é preciso conceber trabalhos que demandem a construção de um conhecimento pelos alunos, a partir de um material existente na internet e que será indicado pelo professor.

Todas estas questões apresentadas nortearam a concepção, a construção e a implementação de uma proposta de uso didático de artigos publicados na Revista virtual de História da Biblioteca Nacional.

Sobre o processo de concepção e construção do trabalho, seu princípio norteador foi o da utilização do site da RHBN para ampliar o estudo da sociedade, cultura e economia das Minas Gerais colonial. Para tanto, foi realizada uma busca e avaliação, em todos os números da Revista disponibilizados on-line de materiais que versassem sobre os temas e o período em questão. No processo de seleção, foram privilegiados os textos que apresentassem recortes históricos e/ou temas distintos dos usualmente

para a Olimpíada Nacional em História do Brasil, organizada pelo Museu de Ciência da Universidade de Campinas. Neste ano de 2012, a Olimpíada encontrase em sua quarta edição. Disponível em: http://www.museudeciencias.com.br/4olimpiada/inicio/index Acesso em 20 set. 2012. 
encontrados nos livros didáticos. Essa escolha prendia possibilitar aos alunos um contato com novos temas e abordagens historiográficas.

Para orientar o acesso ao site da Revista de História, construiu-se um passo a passo, para garantir que mesmo aqueles alunos que tinham pouco contato com a internet tivessem sucesso no cumprimento da tarefa proposta. Os alunos foram também orientados para que acessassem a Plataforma Lattes e buscassem informações sobre o autor do texto em questão. Na apresentação e explicação do trabalho para os alunos, foram expostos os objetivos que nortearam sua elaboração e indicados os passos para sua realização, sendo o primeiro deles a busca do material a ser utilizado:

a) Entre no seguinte site http://rhbn.com.br/v2/home/

b) No site busque e abra o link: Edições Anteriores.

c) Encontre a capa da Revista cujo número corresponde ao indicado para seu grupo e clique sobre ela.

d) Na sequência, procure o título indicado para leitura de seu grupo e clique sobre ele - prepare a apresentação acima conforme indicado.

Para que os alunos obtivessem informações sobre os autores dos textos ${ }^{4}$, eles foram assim orientados:

a) Entre no seguinte site: http://lattes.cnpq.br/

b) No site entre em "buscar currículo" e insira o nome do autor do texto que o grupo leu;

c) Construa uma pequena biografia do autor do texto - o grupo deve apresentar quem é o autor, a instituição à qual está ligado e os trabalhos que já produziu.

Realizada a seleção dos textos e construída a orientação para a busca do texto, era preciso construir o próprio trabalho, ou seja, elaborar as tarefas a serem desenvolvidas pelos alunos. Pretendia-se que a execução do trabalho resultasse, além do conhecimento do site em questão e da

\footnotetext{
${ }^{4}$ Os autores são historiadores.
}

História \& Ensino, Londrina, v. 18, n. 2, p. 293-304, jul./dez. 2012 
leitura do texto indicado, na apropriação do mesmo pelos alunos. Assim, objetivava-se que os alunos redigissem, a partir do material lido, um texto próprio e claro, que demonstrasse um trabalho de reelaboração e reescrita do que fora lido. Para tanto, os alunos foram orientados para redigirem um trabalho escrito estruturado da seguinte maneira:

1. Título do texto - explicar o título dado pelo autor para seu texto (ler o título já é uma primeira leitura do texto) - de 3 a 4 linhas.

2. Apresentação de uma pequena bibliografia do autor do texto - de 3 a 4 linhas.

3. Introdução para apresentar as idéias centrais tratadas no texto de 5 a 10 linhas.

4. Objetivos do autor ao escrever o texto - os objetivos devem ser iniciados sempre com o verbo no infinitivo, por exemplo: retratar, demonstrar, apresentar.

5. Fontes utilizadas pelo autor e a forma como as utilizou para construir sua argumentação/ o texto.

6. Conclusões a que chega o autor - de 5 a 10 linhas.

7. Apreciação pelo grupo do material lido - apresentar um julgamento do grupo sobre o trabalho realizado e a avaliação do material utilizado - de 5 a 10 linhas.

8. Diagramar o texto a ser entregue: fonte Arial, tamanho 10, texto justificado, espaço simples; margem superior e inferior com 2,5 $\mathrm{cm}$;

margem esquerda e direita com $3 \mathrm{~cm}$; não colocar capa no trabalho. Colocar o Cabeçalho na primeira página, com nome da Instituição, logomarca, disciplina, professor e nomes dos alunos que compõem o grupo.

Contudo, antes de mais nada, era preciso construir uma estratégia de apresentação da proposta do trabalho para os alunos, de modo a despertar o interesse da classe. Para motivar os alunos, eles foram levados para uma sala com equipamento de multimídia ligado à internet, onde assistiram a 
uma exposição sobre a história da Biblioteca Nacional (BN) e visitaram seu site. ${ }^{5} \mathrm{~A}$ exploração de alguns dos links ali existentes, objetivava despertar a atenção dos alunos para a importância histórica e contemporânea da Biblioteca e para seu compromisso com a cultura e a produção científica nacional. Publicada pela BN, a Revista de História é uma das sérias iniciativas da Instituição e uma marca de sua decisão para contribuir para a construção e o enriquecimento do conhecimento.

A visita orientada ao site da BN, além de apresentar a própria Instituição, pretendia, simultaneamente, despertar o olhar do educando, apontando-lhe o necessário cuidado que o internauta deve ter com as origens dos sites que visita e com as informações neles contidas.

$\mathrm{Na}$ sequência, visitamos o site da própria Revista de História. ${ }^{6} \mathrm{~A}$ leitura do resumo de um texto publicado no link "Números anteriores", abriu a possibilidade de se questionar com os alunos a autoria dos textos publicados nas páginas da Revista. Para que obtivéssemos informações sobre o autor em questão, sugeriu-se aos alunos uma visita à página da Plataforma Lattes ${ }^{7}$. Quem era aquele autor? Teria ele formação técnica e/ou acadêmica para tratar daquele tema? Certamente o quê estava em pauta era a confiabilidade da própria Revista que publicara o material e que o colocara on-line.

Por fim, a orientação do trabalho foi apresentada em sua íntegra, e os alunos convidados a levar adiante a tarefa proposta. O trabalho em questão tinha uma série de objetivos que foram assim elencados para os alunos:

1) Conhecer a Revista virtual de História da Biblioteca Nacional;

2) Conhecer a Plataforma Lattes e aprender procurar e analisar currículos;

3) Ler, analisar e reelaborar textos historiográficos de divulgação científica;

\footnotetext{
${ }^{5}$ Fundação Biblioteca Nacional. Disponível em:<http://www.bn.br/portal/>. Acesso em 20 set. 2012.

6 Revista de História da Biblioteca Nacional. Disponível em: $<$ http://rhbn.com.br/v2/home/>. Acesso em 20 set.2012.

7 Plataforma Lattes. Disponível em:< http://lattes.cnpq.br/>. Acesso em 20 set. 2012.
} 
4) Ampliar o estudo da economia, cultura e sociedade das Minas Gerais colonial;

5) Preocupar-se com a origem de uma informação e com a seleção de sites para obter informações;

6) Desenvolver um olhar crítico sobre as informações encontradas na web;

7) Desenvolver a capacidade de ler e de reelaborar um texto;

8) Ampliar o nível de interesse e de envolvimento com o processo de ensino-aprendizagem.

Os alunos se organizaram em grupos e prepararam o trabalho escrito solicitado. Cada grupo teve um tempo delimitado para apresentar o que tinham preparado e responder a perguntas dos colegas e da professora.

\section{Considerações finais}

Infelizmente não foi realizado um levantamento quantitativo das avaliações dos alunos sobre as orientações recebidas e 0 trabalho desenvolvido a partir delas. Contudo, a expressão espontânea de duas alunas que se ofereceram para fazer uma apreciação da atividade, aponta para a necessidade de construirmos atividades que permitam a nossos alunos utilizar a riqueza disponível no ciberespaço em atividades pedagógicas. Superando as aulas expositivas e a distância que tem separado a sala de aula do mundo virtual, talvez seja importante que nós professores nos assumamos a necessidade de encarar a internet e o mundo por ela aberto como potenciais aliados do processo de ensinoaprendizagem. Na visão das alunas:

No decorrer deste ano foi desenvolvido conosco, alunos do primeiro ano de Meio Ambiente do CEFET-MG, um trabalho de pesquisa e leitura com base nas reportagens da Revista da Biblioteca Nacional. Este trabalho realizado em grupo proporcionou a mim, a abertura de um leque de conhecimento em história. Fatos que pareciam tolos aos meus olhos poucos 
treinados em conhecimentos aprofundados tornaram se complexos e brilhantes após os trabalhos.

A aluna demonstra que a experiência foi produtiva. Sobre o tema:

Um dos textos com que trabalhamos e me chamou a atenção foi o redigido por Júnia Furtado, chamado 'Pedras da Fortuna'. O texto relatava como Diamantina se formou e como era a cobiça das pessoas que largavam tudo o que tinham e iam para as regiões das minas à procura de diamantes sem nem ao menos ter a certeza de encontrá-los e/ou explorá-los. Além disso, é importante ressaltar sobre o acesso a educação que as pessoas do Arraial do Tijuco possuíam. Outra reportagem que considerei muito interessante foi a reportagem 'Os falsificadores' por Paulo Cavalcante, que explica sobre o contrabando de ouro na colônia e como a culpa deste era "jogada" para a camada desprotegida de leis.

Percebe-se que provavelmente os conhecimentos históricos, além de dispostos com uma formatação capaz de cooptar a aluna, de modo que ela se interesse pelos mesmos, o teor dos artigos faz sentido, ou seja, a aluna lembra-se daqueles temas que talvez estejam mais relacionados à sua experiência e/ou interesses. Outra aluna coloca de forma mais clara a compatibilidade da cultura jovem com a internet:

Durante o ano realizamos muitos trabalhos com diversos temas, dentre eles vários retirados do site da Revista de História da Biblioteca Nacional. Eu e meus colegas tivemos acesso, muitos pela primeira vez, a um acervo que a maioria nem sabia que existia. Foi bastante fácil trabalhar e aprender com os artigos da Revista, por se tratar de algo que nós jovens estamos acostumados a mexer. Esse novo acesso a informação pela Revista, pelo site, faz com que os adolescentes enxerguem o estudo como forma de diversão. Sabemos da credibilidade que os autores dos artigos possuem no ramo da história e isso passa mais segurança às nossas apresentações e seminários. Essa interatividade proporcionada pelo site faz com que outros temas possam ser introduzidos ao seu trabalho, dando mais conhecimento a você e aos seus ouvintes nas salas de aula. Os trabalhos realizados com o uso da Revista de História da Biblioteca Nacional são, sem dúvida, uma maneira lúdica de aprendizado, muito importante para criar interesse nos alunos na "era" da comunicação. Creio que trabalhos como esse devem ser repetidos devido aos grandes resultados. Particularmente achei incrível a maneira como são tratados os temas e a certa profundidade que abordam. Para mim, essa deveria ser a maneira de se ensinar e aprender HISTÓRIA. 
Enfim, a RHBN impressa ou virtual, são formas de divulgação do conhecimento histórico, então mais pertinente à cultura não só dos jovens, mas de um grande público. Por isso a aluna entende que "aprende história" com este material. De certo, uma história mais "compreensível", embora seja escrita por historiadores preocupados em ir além da história escrita somente para os pares.

\section{Referências Bibliográficas:}

BITTENCOURT, C. M. F. de. Métodos e novas tecnologias. In: BITTENCOURT, C. M. F. de. Ensino de História: fundamentos e métodos. São Paulo: Cortez, 2004.

CHEVALLARD, Y. La transposition didactique: du savoir savant au savoir enseigné. Paris: La Fenseé Sauvage, 1991.

Era Virtual Museus. Disponível em: http://www.eravirtual.org/pt/ Acesso em 20 set. 2012.

Fundação Biblioteca Nacional. Disponível em:<http://www.bn.br/portal/>. Acesso em 20 set. 2012.

Olimpíada Brasileira de História do Brasil. Disponível em: <http://www.museudeciencias.com.br/4-olimpiada/inicio/index>. Acesso em 20 set. 2012.

Plataforma Lattes. Disponível em: < http://lattes.cnpq.br/>. Acesso em 20 set. 2012.

Revista de História da Biblioteca Nacional. Disponível em: <http://rhbn.com.br/v2/home/>. Acesso em 20 set.2012.

SILVA, Marcos. Ensino de história e novas tecnologias. Disponível em:

http://www.educadores.diaadia.pr.gov.br/arquivos/File/fevereiro2012/histor ia artigos/2silva artigo.pdf Acesso em 20 set. 2012. 